\title{
Analysis of diversity in rice (Oryza sativa L.) using random amplified polymorphic DNA (RAPD) and simple sequence repeats (SSR) markers
}

\author{
Harsh Bansal ${ }^{1}$, Ravindra Kumar ${ }^{1 *}$, Vivek ${ }^{2}$ and Sanjay ${ }^{3}$ \\ ${ }^{1}$ Department of Fingerprinting,Sardar Vallabhbhai Patel University of Agriculture And Technology,Modipuram, Meerut, \\ (U.P), India. \\ ${ }^{2}$ Department of Agronomy, Sardar Vallabhbhai Patel University of Agriculture And Technology,Modipuram, Meerut, \\ (U.P), India. \\ ${ }^{3}$ Division of Genetics, Indian Agriculture Research Institute, New Delhi, India.
}

Accepted 17 July, 2013

\begin{abstract}
Molecular markers are useful tool for assessing genetic variations and resolving genotype identity. In the current study, genetic diversity among 20 rice genotypes was assessed using the random amplified polymorphic DNA (RAPD) and simple sequence repeat (SSR). In RAPD analysis, 20 primers generated a total of 116 bands of which 114 were polymorphic. The number of amplification products produced by each primer varied from 4 to 7 with an average of 5.8 bands per primer. Twenty (20) SSR primers generated a total of 65 alleles with an average 3.2 alleles per primer. Genetic diversity of 20 genotypes estimated by polymorphic information content (PIC) value ranged from 0.62 to 0.97 in SSR and 0.33 to 0.88 with RAPD analysis. The cluster dendrogram by SSR revealed two major clusters. Rajeshwari was the only genotype in cluster I. The cluster II further divided into two sub clusters IIA and IIB. II A consisted of 17 genotypes while II B consisted of two genotypes (Apo and Kalakeni). The information generated from this study can be used to maximize selection of diverse parents and broaden the germplasm base for the future rice breeding programs.
\end{abstract}

Key words: Genetic diversity, molecular markers, rice, markers based estimation of genetic diversity in rice.

\section{INTRODUCTION}

Rice (Oryza spp.) is one of the most important food crops in the world, being planted on almost $11 \%$ of the Earth's cultivated land area over a wide number of ecosystems (Cuevas and Fitzgerald, 2012). Rice belongs to the genus Oryza and has two cultivated and 22 wild species.
Rice is an ideal model plant for the study of grass genetics and genome organization due to its diploid genetics, relatively small genome size of $430 \mathrm{Mb}$ (Causse et al., 1994), significant level of genetic polymorphism (McCouch et al., 1998), large amount of well conserved genetically

\footnotetext{
*Corresponding author. E-mail: kumarrk2000@yahoo.com.
}

Abbreviations: DNA, Deoxyribonucleic acid; CTAB, cetyl tri-methyl ammonium bromide; PCR, polymerase chain reaction; TE, Tris acetate; EDTA, ethylenediamine tetra acetic acid; RAPD, random amplified Polymorphic DNA, SSRs, simple sequence repeats; dNTPs, deoxyribonucleotide tri phosphate. 
diverse material (about 100,000 accessions world wide) and the availability of widely collected compatible wild species. The success of breeding program also depends upon the amount of genetic variability present in the population and extent to which the desirable traits are heritable. The assessment of phenotype may not be a reliable measure of genetic differences. The rapid development of biotechnology allows easy analysis of a large number of loci distributed throughout the genome of plants. Molecular markers have proven to be powerful tool in the assessment of genetic variation and in the elucidation of genetic relationships within and among species (Matin et al., 2012). Molecular markers originate from different parts of the genome including coding and non-coding regions and can cover either the full genome or large genomic segments. Morphological traits are controlled by a relatively small number of loci (Onaga et al., 2013) however; they serve as a valuable guide for effective collection and use of genetic resources. Molecular markers (RAPD) without prior knowledge of DNA sequences are especially useful for unzipping the variations in species with low genetic variability. RAPD markers are considered to be unbiased and neutral markers for genetic mapping applications, in population genetics, taxonomy as well as for genetic diagnostics. Microsatellites are the popular molecular markers in rice for various applications in genetics and breeding. SSR markers are important tool for estimation of genetic variation and identification of germplasm. These markers have some merits like quickness, simplicity, rich polymorphism and stability, thus being widely used in molecular map construction and gene mapping, construction of fingerprints and genetic purity test (Ma et al., 2011), analysis of germ plasm diversity (Jin et al., 2010 ), utilization of heterosis, especially in identification of species with closer genetic relationship. SSR markers are more popular in rice because they are highly informative, mostly monolocus, co dominant, easily analyzed and cost effective (Prabakaran et al., 2010). Using PCR rapid amplification and gel electrophoresis of high resolving power, we can test SSR length polymorphism rapidly and economically. In the current studies, RAPD, SSR and combined analysis was performed to assess the genetic diversity among 20 genotypes of rice.

\section{MATERIALS AND METHODS}

\section{Plant material}

Leaf samples of 20 rice genotypes ( 25 days after transplanting.) were collected from the Genetics Division, Indian Agriculture research institute, Delhi, India from wet season 2010. The details of rice genotypes are presented in Table 1.

\section{DNA extraction}

Total DNA was extracted from fresh leaves by the cetyl tri-methyl ammonium bromide (CTAB) method (Murray and Thompson, 1980). The quality and concentration of extracted DNA were estimated by using a UV-Vis spectrophotometer. The DNA was spooled out, washed twice with $70 \%$ ethanol and dissolved in TE (10 mM Tris, $0.1 \mathrm{mM}$ EDTA, pH 8.0) containing $25 \mu \mathrm{g} / \mathrm{ml}$ RNase-A, incubated at $37^{\circ} \mathrm{C}$ for $30 \mathrm{~min}$ and extracted with chloroform:isoamyl alcohol (24:1 v/v). DNA was re-precipitated and dissolved in TE buffer. DNA was checked for its quality and quantity by $0.8 \%$ agarose gel electrophoresis.

\section{PCR analysis and gel electrophoresis}

In case of SSR, a set of 20 primers (Chakravarthi et al., 2006) were used. The details of primers used for SSR analysis are presented in Table 2. The PCR reaction was carried out using Taq polymerase (Genei) in $20 \mathrm{ml}$ reaction volume containing 1.5X PCR buffer, $2 \mathrm{mM}$ $\mathrm{MgCl}_{2}, 0.02 \mathrm{mM}$ of each dNTPs, $1 \mathrm{mM}$ of forward and reverse primers, $0.5 \mu \mathrm{l}$ (3 unit) Taq polymerase and $50 \mathrm{ng}$ genomic DNA. Profile used was as follows: an initial hot start and denaturing step at $95^{\circ} \mathrm{C}$ for $5 \mathrm{~min}$ followed by 35 cycles at $94^{\circ} \mathrm{C}$ for $1 \mathrm{~min}$, appropriate annealing temperature $55^{\circ} \mathrm{C}$ for $1 \mathrm{~min}$, and primer elongation at $72^{\circ} \mathrm{C}$ for $2 \mathrm{~min}$. Final extension step at $72^{\circ} \mathrm{C}$ for $7 \mathrm{~min}$ was performed.

RAPD analysis was performed according to Williams et al. (1990) with minor modifications. The primers used for RAPD are given in Table 3. PCR reactions were carried out in $20 \mu \mathrm{l}$ volume containing $50 \mathrm{ng}$ of total genomic DNA, 10 pmol primer, $200 \mu \mathrm{M}$ dNTPs, $2 \mathrm{mM}$ $\mathrm{MgCl} 2$, 2.5X PCR buffer and $0.4 \mu \mathrm{l}$ ( 3 units) AmpliTaq Polymerase. Twenty (20) 10-mer oligonucleotide random primers were selected for analysis. These primers were obtained from Banglore Genei, India. Amplification was performed in a Astec thermal cycler with the following profile: $94^{\circ} \mathrm{C}$ for $4 \mathrm{~min}$ (initial denaturation), $94^{\circ} \mathrm{C}$ for 1 $\min , 32^{\circ} \mathrm{C}$ for $1 \mathrm{~min}, 72^{\circ} \mathrm{C}$ for 2 min for 42 cycles with a final extension at $72^{\circ} \mathrm{C}$ for $7 \mathrm{~min}$.

The RAPD-PCR products were analyzed directly on $1.5 \%$ agarose gels in TAE buffer while SSR-PCR products were analyzed on $4 \%$ agarose gel, visualized by staining with ethidium bromide under short-wave UV light. DNA ladder used in the electrophoresis was of $100 \mathrm{bp}$. Agrose gel electrophoresis for PCR products of RM222, SSR marker and OPA-07, RAPD marker is shown in Figure 4 and 5 respectively.

\section{Data analysis}

Pair wise comparison of genotypes, based on the presence (1) or absence $(0)$ of unique and shared polymorphic products was used to generate similarity coefficients of Jaccord's coefficient by NTSYS-pc version 2.1 software (Rohlf, 2000). The similarity coefficient was used to construct a dendrogram by the unweighted pair group method with arithmetic averages (UPGMA) according to Rohlf (1993). The polymorphism information content (PIC) value described by Botstein et al. (1980) and modified by Anderson et al. (1993) for self-pollinated species was calculated as follows:

$\mathrm{PIC}_{i}=1-\sum_{j=1}^{n} P_{i j}^{2}$

Where, $p_{i}$ equals to the frequency of the th allele and $p_{j}$ the frequency of the allele. Only data from polymorphic loci were used for analysis. 
Table 1. Characteristics of rice genotypes used in investigation.

\begin{tabular}{|c|c|c|}
\hline Name of Variety & Sources/origin & Characteristic features \\
\hline Apo & IRRI, Philippines & Suitable for aerobic cultivation, larger and fuller grains, tall \\
\hline Kalakeni & Orissa, India & Semi dwarf, Grain, long slender, tolerant to alkalinity. \\
\hline Satabdi & West Bengal, India & Semi-dwarf, grains: LS, white, resistant to Sh.B, BB \& Sh.R; \\
\hline Ratna & Orissa, India & Dwarf, long slender and white grain. Moderately resistant to blast, leaf hopper and tolerant to stem borer. \\
\hline Khandagini & Orrisa, India & Semi dwarf grains- LS, white tolerant to blast, BPH \& GM; \\
\hline IR-36 & IRRI, Philippines & Medium duration, irrigated, rain fed upland or lowland areas. semi dwarfs, grain long slender and white. \\
\hline Swarna & Andhra Pradesh, India & Semi dwarf, grains: LS, resistant to blast, WBPH, moderately resistant to SB \\
\hline IR-64 & IRRI, Philippines & Semi dwarfs, mid/long duration \\
\hline Safri -17 & Chattisgarh, India & Tall, grains -LB, resistant to blast, BPH \& BLB \\
\hline Lalat & Orrisa, India & Semi dwarfs grains - LS, white, resistant to blast, Suitable for aerobic and boro conditions \\
\hline Khitish & West Bengal, India & Dwarf , grains: LS, moderately resistant to blast \& BS, \\
\hline Naveen & Orissa, India & Medium duration \\
\hline Suskhasmanat & Bihar, Jharkhand, India & Tall, grains: short bold, white, susceptible to blast, BLB and resistant to drought \\
\hline Sambhamahsuri & Andhra Pradesh, India & Semi dwarf grains -MS, tolerant to SB,GM \& RTV; resistant to blast \\
\hline Samanta & Andra Pradesh, India & Semi dwarf short duration lodging \& disease resistance \\
\hline Dandi & Gujrat, India & Semi dwarf, grains-MB, white, moderately resistant to Sh.B, BS,BPH,\& BPH \\
\hline Rajeshwari & Orissa, India & Semi dwarf, grains- MB, white, resistant to blast \& BLB \\
\hline Shravani & Jharkhand, India & Grains-LS, white; resistant to blast, Helminthosporium, tolerant to BLB, susceptible to RTV \\
\hline Abhishek & Jharkhand, India & Medium duration \\
\hline Udaya & Orissa, India & Semi dwarf grains: long bold, resistant to $\mathrm{BPH}$, blast, root rot and tolerant to RTV; \\
\hline
\end{tabular}

\section{RESULTS AND DISCUSSION}

\section{SSR analysis}

In present study, 20 SSR primers distributed from chromosome 7 to 12 were used to estimate genetic diversity among 20 genotypes. A total of 65 alleles were detected among all genotypes. The number of alleles per locus varied from 2 to 7 . The mean allele in current studies (3.25 alleles) was comparable with the results of Etemad et al. (2012) as 3.57 in rice. However, it was reported lower by
Prathepha et al. (2012) and Rahman et al. (2012) with an average of 11.85 and 4.18 alleles per locus, respectively.

The overall size of amplified products ranged from 100 (RM264) to 250 bp (RM286). In the current studies, 15 out of 20 SSR primer pairs generated polymorphic bands. PIC values for SSR ranged from 0.62 to 0.97 with mean value of 0.81 (Table 4). The highest PIC value was observed with primer RM-222 and RM-206 (0.97). However, it varied from 0.19 to 0.90 with an average of 0.75 as reported by Borba et al. (2009). About similar
averagePICvalues (0.78) was reported by Upadhyay et al. (2011). The cluster analysis showed a significant genetic variation among the genotypes with similarity coefficients ranging from 0.63 to 0.85 (Figure 1). The dendrogram revealed two distinct clusters at a similarity coefficient level of 0.63 . Cluster II was the largest and included 19 genotypes while, clusters I comprised only one genotype, that is, Rajeshwari. The cluster II further divided into two sub clusters IIA and IIB. II A consisted of 17 genotypes while II B consisted of only two genotypes (Apo and Kalakeni). Apo and 
Table 2. List of RAPD Primers used for the analysis of twenty rice genotypes.

\begin{tabular}{llll}
\hline Code & Primer sequences 5'-3' & Code & Primer sequences 5'-3' \\
\hline OPA-04 & AATCGGGCTG & OPA-16 & AGCCAGCGAA \\
OPA-07 & GAAACGGGTG & OPA-17 & GACCGCTTGT \\
OPA-08 & GTGACGTAGG & OPA-18 & AGGTGACCGT \\
OPA-09 & GGGTAACGCC & OPA-19 & CAAACGTCGG \\
OPA-10 & GTGATCGCAG & OPA-20 & GTTGCGATCC \\
OPA-11 & CAATCGCCGT & OPB-06 & TGCTCTGCCC \\
OPA-12 & TCGGCGATAG & OPB-07 & GGTGACGCAG \\
OPA-13 & CAGCACCCAC & OPB-08 & GTCCACACGG \\
OPB-11 & GTAGACCCGT & OPB-17 & AGGGAACGAG \\
OPB-13 & TTCCCCCGCT & OPB-18 & CCACAGCAGT \\
\hline
\end{tabular}

Table 3. List of SSR Primers and their sequences used for the analysis of twenty rice genotypes.

\begin{tabular}{lll}
\hline \multirow{2}{*}{ Primer code } & \multicolumn{2}{c}{ Primer sequences 5'-3' } \\
\cline { 2 - 3 } & Forward & Reverse \\
\hline RM 21 & ACAGT AT TCCGTAGACGG & GCTCCATGAGGG TGGTA AG \\
RM 536 & TCTCTCCTCTTGTTTGGCTC & ACACACCAACACGACCACAC \\
RM 206 & CCCATGCGTTTAACATTC T & CGTTCCATCGATCCGTATGG \\
RM 566 & ACCCAACTACGATCATCG & CTCCAGGAACACGCTCTTTC \\
RM 320 & CAACGTGATCGAGGAGAT C & GGATTTGCTTACCACAGCTC \\
RM 247 & TAGTGCCGATCGATGTA ACG & CATATGGTTTTGACAAAGCG \\
RM 544 & TGTGAGCCTGAGCAAT AACG & GAAGCGTGTGATATCGCATG \\
RM 346 & CGAGAGAGCCCATAACTACG & ACAAGACGACGAGGAGGGAC \\
RM 547 & TAGGTTGGCAGACCTTTTCG & GTCAAGATCATTCTCGTAGCG \\
RM 519 & AGAGAGCCCCTAAATTT CCG & AGGTACGCTCACCTGTGGAC \\
RM 286 & GGCTTCATCTTTGGCGAC & CCGGATTCACGAGATAAACTC \\
RM 581 & GAGCTGTTTTGGACTACGGC & GAGTAGCTTTCTCCCACCCC \\
RM 222 & CTTAAATGGGCCACATGCG & CAAAGCTTCCGGCCAAAAG \\
RM 47 & ACTCCACTCCACTCCCCA & GTCAGCAGGTCGGACGTC \\
RM 10 & TTGTCAAGAGGAGGCATCG & CAGAATGGGAAATGGTCC \\
RM 19 & CA AAAACAGAGCAGATGAC & CTCAAGATGGACGCCAAGA \\
RM 20 & ATCTTGTCCCTGCAGGTCAT & GAAACAGAGGCACATTTCATTG \\
RMR & ACGAGCTCTCGATCAGCCTA & TCGGTCTCCATGTCCCAC \\
RM 167 & GATCCAGCGTGAGGAACACGT & AGTCCGACCACAAGGTGCGTTGTC \\
RM 264 & GTTGCGTCCTACTGCTACTTC & GATCCGTGTCGATGATTAGC \\
\hline
\end{tabular}

Rajeshwari were distantly related at a similarity coefficient of 0.63. Cluster analysis showed that Satabdi and Ratna showed maximum similarity with the similarity coefficient of 0.85 . Based on dendrogram, the genotypes Apo, Samantha and Rajeshwari belong to different clusters and are genetically diverse.

\section{RAPD analysis}

Using 20 RAPD primers, a total of 116 alleles were detected among the 20 rice genotypes. The number of alleles per locus varied from 4 to 7 . The average number of alleles per locus was 5.8. The overall size of amplified products ranged from 100 (OPA-10) to $1200 \mathrm{bp}$ (OPA11). All the RAPD primers used for analysis of genetic diversity and relationship generated polymorphic bands among the genotypes. The PIC value for the RAPD ranged from 0.33 to 0.88 with an average of 0.65 (Table $5)$. Similar results were also reported by Shiva et.al. (2013) in rice. The present investigation revealed the effectiveness of RAPD in detecting polymorphism among different genotypes of rice. Nair et al. (2013) also reported 
Table 4. Polymorphism Information Content (PIC) of SSR Loci across various genotypes.

\begin{tabular}{|c|c|c|c|c|c|c|c|c|}
\hline Primer & $\begin{array}{c}\text { Chromosomal } \\
\text { location }\end{array}$ & Motifs & $\begin{array}{l}\text { Molecular weight } \\
\text { range (bp) }\end{array}$ & $\begin{array}{c}\text { Total number } \\
\text { of alleles }\end{array}$ & $\begin{array}{c}\text { Number of } \\
\text { Polymorphic alleles }\end{array}$ & $\begin{array}{c}\text { Number of monomorphic } \\
\text { alleles }\end{array}$ & $\begin{array}{c}\% \\
\text { Polymorphism } \\
\end{array}$ & $\begin{array}{l}\text { Diversity in value } \\
\text { of PIC } \\
\end{array}$ \\
\hline RM21 & 11 & (GA)18 & $130-190$ & 5 & 5 & 0 & 100.00 & 0.90 \\
\hline RM536 & 11 & (CT)16 & $150-240$ & 4 & 4 & 0 & 100.00 & 0.88 \\
\hline RM206 & 11 & (CT)21 & $200-140$ & 7 & 7 & 0 & 100.00 & 0.97 \\
\hline RM566 & 9 & (AG) 15 & $250-200$ & 4 & 4 & 0 & 100.00 & 0.74 \\
\hline RM320 & 7 & (AT)11GTAT(GT13) & $250-150$ & 6 & 6 & 0 & 100.00 & 0.94 \\
\hline RM247 & 12 & (CT)16 & $250-210$ & 4 & 4 & 0 & 100.00 & 0.93 \\
\hline RM544 & 8 & $(\mathrm{TC}) 9$ & $180-130$ & 2 & 2 & 0 & 100.00 & 0.68 \\
\hline RM346 & 7 & (CTT) 18 & $200-100$ & 5 & 5 & 0 & 100.00 & 0.94 \\
\hline RM547 & 8 & (ATT) 19 & $100-280$ & 5 & 5 & 0 & 100.00 & 0.90 \\
\hline RM519 & 12 & $(\mathrm{AAG}) 8$ & 150 & 1 & 0 & 1 & 0.00 & 0.00 \\
\hline RM286 & 11 & $(G A) 16$ & $100-150$ & 5 & 5 & 0 & 100.00 & 0.96 \\
\hline RM581 & - & $(\mathrm{GA}) 12$ & $200-150$ & 3 & 3 & 0 & 100.00 & 0.90 \\
\hline RM222 & 10 & (CT)18 & $150-250$ & 4 & 4 & 0 & 100.00 & 0.97 \\
\hline RM47 & 7 & $(A G) 7(A G) 11$ & $200-250$ & 6 & 6 & 0 & 100.00 & 0.96 \\
\hline RM10 & 7 & $(\mathrm{GA}) 15$ & 160 & 1 & 0 & 1 & 100.00 & 0.00 \\
\hline RM19 & 12 & (ATC)10 & 250 & 1 & 1 & 0 & 100.00 & 0.00 \\
\hline RM20 & 12 & (ATT) 14 & - & 0 & 0 & 0 & 0.00 & 0.00 \\
\hline RMR & - & - & - & 0 & 0 & 0 & 0.00 & 0.00 \\
\hline RM167 & 11 & $(\mathrm{GA}) 16$ & - & 0 & 0 & 0 & 0.00 & 0.00 \\
\hline RM264 & 8 & $(G A) 27$ & $100-150$ & 2 & 2 & 0 & 100.00 & 0.62 \\
\hline
\end{tabular}

that RAPD analysis in $O$. sativa accessions can be successfully used to estimate the genetic diversity in rice.

The highest PIC value (0.88) was observed for primers OPA-17. Cluster analysis revealed two major clusters at a cut-off similarity coefficient of 0.57 (Figure 2). Cluster I was largest and included 14 genotypes while cluster II consisted of six genotypes. Jaccard's coefficient of similarity revealed that $83.8 \%$ exist between genotypes
Shravani and Abhishek. Whereas, Apo keeps very low level of similarity with Rajeshwari at similarity coefficient of $0.57 \%$. The major cluster I further divided into two sub clusters IA and IB. The sub cluster IA consist of 10 genotypes namely Khitish, Naveen, Udaya, Sukhasamat, Shravani, Abhishek, Sambhamasuri, Dandi,Samanta and Rajeshwari with the similarity coefficient ranged between 0.62 to 0.83 . While sub cluster IB consist of 4 genotypes namely Swarna, IR-64, Safri and Lolut with similarity coefficient from 0.67 to 0.78 .

\section{Combined analysis}

The cluster dendrogram with combined analysis revealed two major clusters. Cluster I was the largest and included 14 genotypes, namely Swarna. IR64, Lolat, Safri, Suskhasamanat, Khitis, Naveen, Sambhamasuri, Dandi, Samanta, Rajaewari, Shravani, Abhishek and Udaya with the similarity 


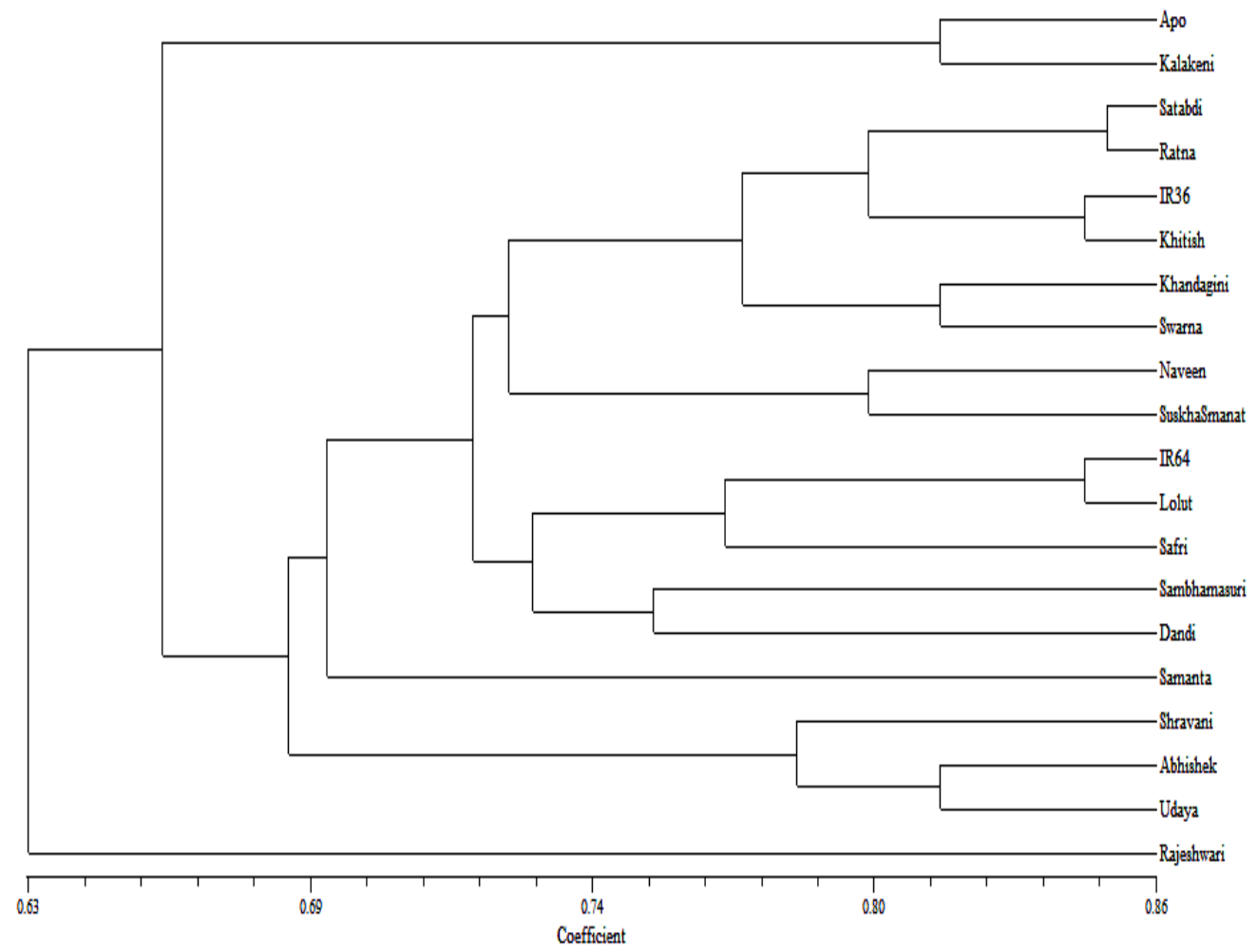

Figure 1. Dendrogram showing clustering of 20 genotypes of rice genotypes based on SSR data.

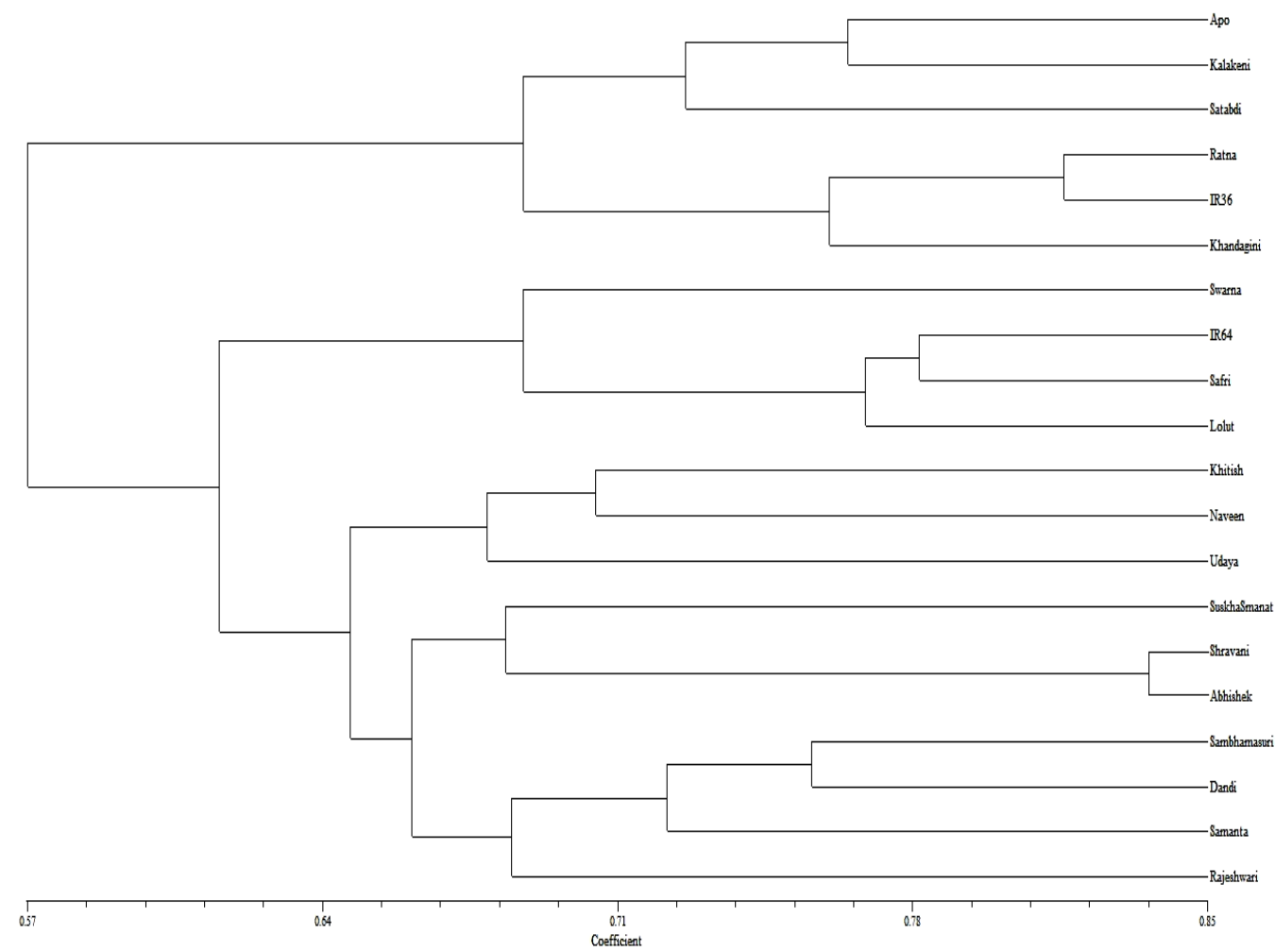

Figure 2. Dendrogram showing clustering of 20 genotypes of rice genotypes based on RAPD data. 
Table 5. Polymorphism information content (PIC) of RAPD loci across various genotypes.

\begin{tabular}{|c|c|c|c|c|c|c|c|}
\hline Primer & $\begin{array}{c}\text { Annealing } \\
\text { temperature }\end{array}$ & $\begin{array}{l}\text { Molecular weight range } \\
\text { (bp) }\end{array}$ & $\begin{array}{c}\text { Total number } \\
\text { of alleles }\end{array}$ & $\begin{array}{c}\text { Number of } \\
\text { polymorphic alleles }\end{array}$ & $\begin{array}{c}\text { Number of } \\
\text { Monomorphic alleles } \\
\end{array}$ & $\begin{array}{c}\% \text { of } \\
\text { polymorphism }\end{array}$ & PIC \\
\hline OPA-04 & 30 & $350-800$ & 5 & 5 & 0 & 100.00 & 0.64 \\
\hline OPA-07 & 30 & $200-700$ & 7 & 7 & 0 & 100.00 & 0.68 \\
\hline OPA-08 & 30 & $200-1100$ & 5 & 4 & 1 & 80.00 & 0.33 \\
\hline OPA-09 & 32 & $100-1000$ & 5 & 4 & 1 & 80.00 & 0.46 \\
\hline OPA-10 & 30 & $100-800$ & 6 & 6 & 0 & 100.00 & 0.64 \\
\hline OPA-11 & 30 & $100-1200$ & 5 & 5 & 0 & 100.00 & 0.66 \\
\hline OPA-12 & 30 & $200-800$ & 7 & 7 & 0 & 100.00 & 0.72 \\
\hline OPA-13 & 32 & $150-700$ & 5 & 5 & 0 & 100.00 & 0.62 \\
\hline OPA-16 & 30 & $300-700$ & 5 & 5 & 0 & 100.00 & 0.77 \\
\hline OPA-17 & 30 & $200-1000$ & 6 & 6 & 0 & 100.00 & 0.88 \\
\hline OPA-18 & 30 & $250-600$ & 5 & 5 & 0 & 100.00 & 0.82 \\
\hline OPA-19 & 30 & $400-1000$ & 7 & 7 & 0 & 100.00 & 0.66 \\
\hline OPA-20 & 30 & $400-900$ & 7 & 7 & 0 & 100.00 & 0.64 \\
\hline OPB-06 & 32 & $300-800$ & 4 & 4 & 0 & 100.00 & 0.67 \\
\hline OPB-07 & 32 & $200-800$ & 5 & 5 & 0 & 100.00 & 0.69 \\
\hline OPB-08 & 32 & $200-550$ & 6 & 6 & 0 & 100.00 & 0.79 \\
\hline OPB-11 & 30 & $300-800$ & 6 & 6 & 0 & 100.00 & 0.76 \\
\hline OPB-13 & 32 & $300-700$ & 6 & 6 & 0 & 100.00 & 0.78 \\
\hline OPB-17 & 30 & $200-900$ & 7 & 7 & 0 & 100.00 & 0.86 \\
\hline OPB-18 & 30 & $300-1000$ & 7 & 7 & 0 & 100.00 & 0.59 \\
\hline
\end{tabular}

coefficient that ranged between 0.65 to 0.82 while clusters II comprised six genotypes namely Apo, Kalakeni, Satabdi, Ratna, IR36 and Khandagini with the similarity coefficient ranging from 0.69 to 0.82 (Figure 3). Jaccard's coefficient of similarity revealed that high degree of similarity up to the extent of $82.1 \%$ existed between IR36 and Ratna. Dendrogram revealed that Apo was distantly located with Udaya with similarity coefficient of 0.62. Dendrogram revealed that genotypes Swarna, Satabdi, and Sukhasmanat, Samanta,
Rajeshwari, Udaya and Apo belong to different clusters and are genetically diverse. SSR markers showed higher PIC value compared to RAPD which indicates that SSR markers are highly informative and are reliable. In the current study, larger range of distinct values for genotypes revealed by microsatellite markers provides greater confidence for the assessments of genetic diversity and relationships, which can be used in future breeding programs. With the aid of microsatellite makers and clustering data, different distantly related rice genotypes may be combined by intercrossing genotypes, for instance, aromatic rice genotypes with non-aromatic rice genotypes from different clusters to get hybrid varieties with highest heterosis (Sajib et al., 2012). Markers with PIC values of 0.5 or higher are highly informative for genetic diversity studies and can be successfully used to distinguish the polymorphism at a specific locus. The joint use of primer is excellent way of identification of genotypes. A combination of RAPD and SSR help to provide whole genome coverage and 


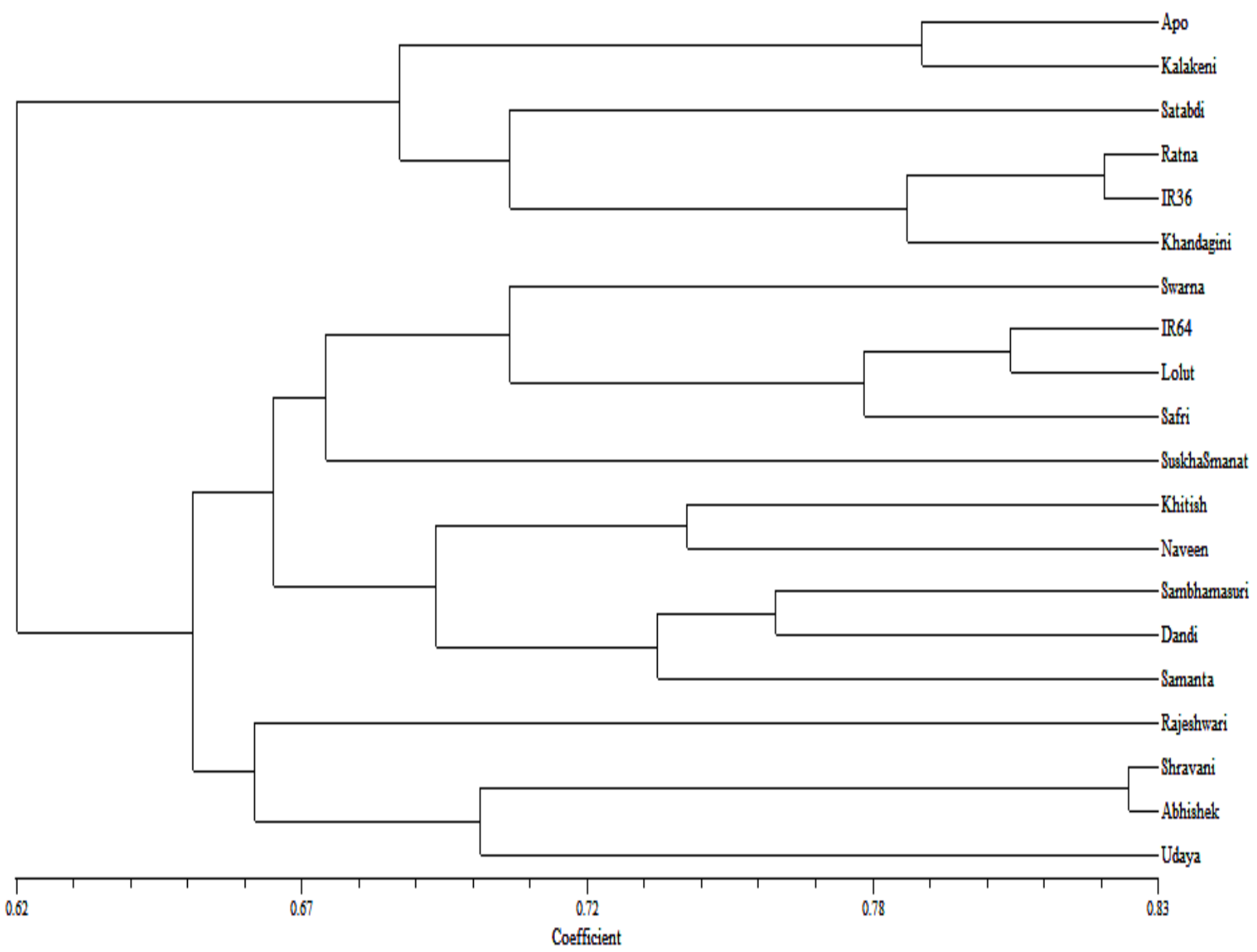

Figure 3. Dendrogram showing clustering of 20 genotypes of rice based on combined (SSR and RAPD) data.

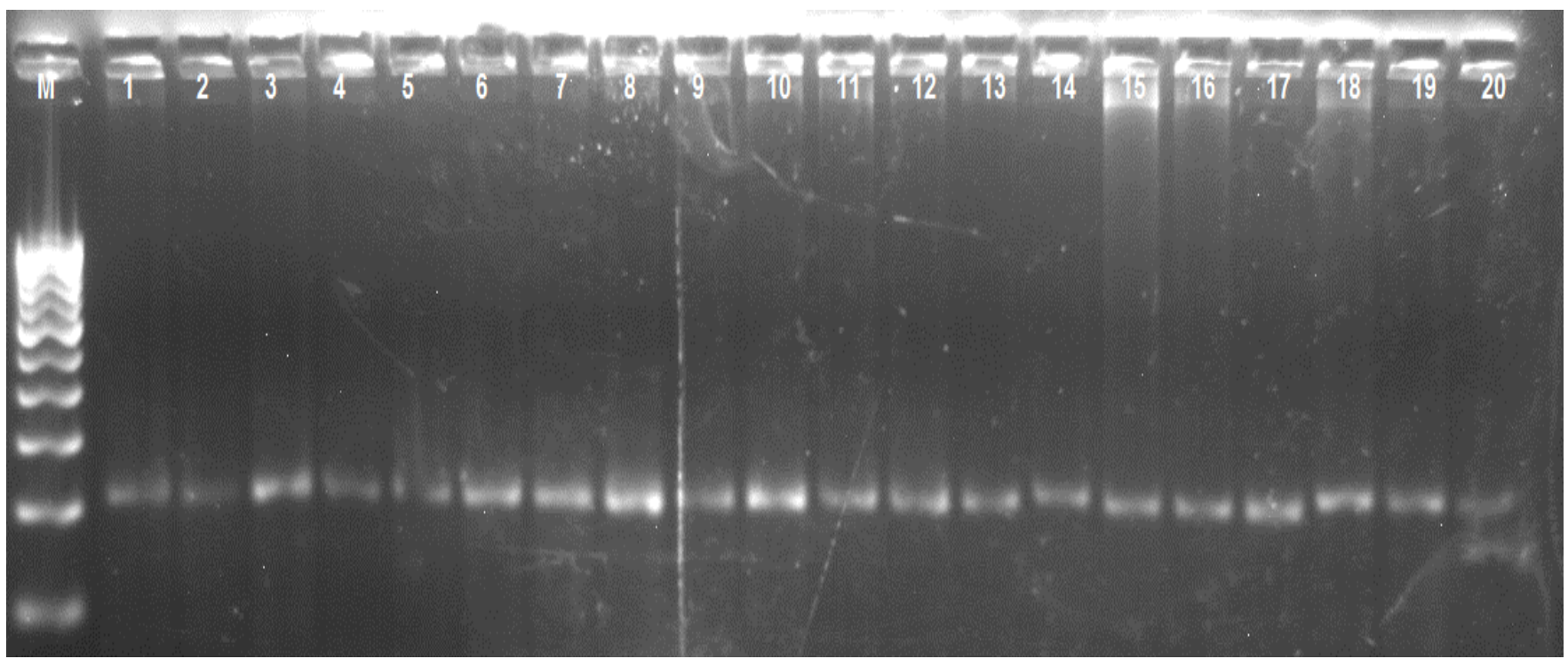

Figure 4. Agrose gel electrophoresis for PCR products of SSR marker (RM-222) of 1 - 20 rice genotypes (As described in Table 1). $M=D N A$ ladder (100 bp). 


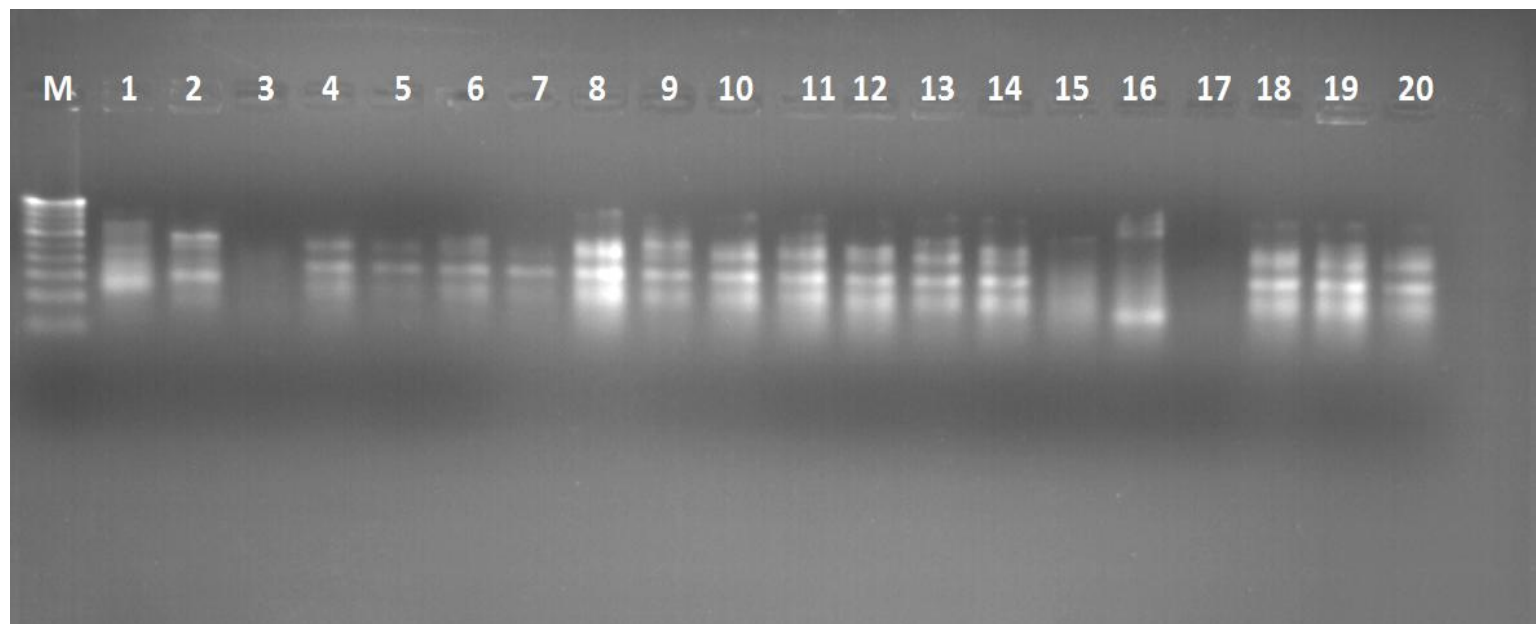

Figure 5. Agrose gel electrophoresis for PCR products of RAPD marker (OPA-07) of 1 - 20 rice genotypes (as described in Table 1). M=DNA ladder (100 bp).

and reduce the error in estimation of genetic similarity based on any one marker system alone.

\section{ACKNOWLEDGEMENTS}

The technical help provided by Mrs. Rekha Satpuri, Technician and Mr. Ashwani Kumar Singh, Senior Research Fellow during the course of investigation is gratefully acknowledged. Financial help provided by SVPUA\&T, Meerut is also gratefully acknowledged.

\section{REFERENCES}

Anderson JA, Churchill GA, Autrique JE, Tanksley SD, Sorrells ME (1993). Optimizing parental selection for genetic linkage maps. Genom. 36:181-6.

Botstein D, White R, Skolnick M, Davis R (1980). Construction of genetic linkage map in man using restriction fragment length polymorphism. Am. J. Genet. 32:314-331.

Causse M, Fulton TM, Cho YG, Ahn SN, Chunwonge J, Wu J, Xiao ZY Ronald PC (1994). Saturated molecular map of rice genome based on inter specific back cross. Phyto. pathol. 85:1251-1274.

Chakravarthi KB, Rambabu N (2006). SSR marker based DNA fingerprinting and diversity study in rice (Oryza sativa L.). Afr. J. Biotechnol. 5:684-688.

Cuevas RP, Fitzgerald MA (2012). Genetic Diversity of Rice Grain Quality Grain Quality and Nutrition Centre, Int. Rice Res. Inst. Philippines 15:285-310.

Etemad A, Maziah M, Daud SK (2012). Determination of genetic relatedness among selected rice (Oryza sativa, L.) cultivars using microsatellite markers. Afr. J. Biotechnol. 11(28):7158-7165.

Jin L, Lu Y, Xiao P, Sun M, Corke H, Bao J (2010). Genetic diversity and population structure of a diverse set of rice germplasm for association mapping. Theor. Appl. Genet. 121(3):475-487.

Ma H, Yin Y, Guo ZF, Cheng LJ, Zhang L, Zhong M, Shao GJ (2011). Establishment of DNA fingerprinting of Liaojing series of japonica rice. Middle-East J. Sci. Res. 8(2):384-392.
Matin S, Mohmmad A, Islam MM, Sikdar SU, Zobayer N (2012). Molecular marker based (SSR) genetic diversity analysis in deep water rice germplasms of Bangladesh. Int. J. Biosci. 10(2):64-72

McCouch SR, Kochert G, Yu ZH, Wang ZY, Khush GS, Coffman WR, Tanksley SD (1998). Molecular mapping of rice chromosomes. Theor. Appl. Genet. 76:815-829.

Murray MG, Thompson WF (1980). Rapid isolation of high molecular weigh plant DNA. Nucleic Acids Res. 8:4321-4325.

Nair GM, Nair AJ, Rajani J, Deepu V (2013). Molecular characterization of selected cultivars of rice, Oryza sativa L. using Random Amplified Polymorphic DNA (RAPD) markers. Int. Food Res. J. 20(2):919-923.

Onaga G, Egdane J, Edema R, Abdelbagi I (2013). Morphological and Genetic Diversity Analysis of Rice Accessions (Oryza sativa L.) Differing in Iron Toxicity Tolerance. J. Crop Sci. Biotech. 16(1):53-62.

Prabakaran A, Paramasivam K, Rajesh T, Rajarajan D (2010). Molecular characterization of rice land races using SSR markers. Electron. J. Plant Breed. 1(4):512-516.

Prathepha $P(2012)$. Genetic diversity and population structure of wild rice, Oryza rufipogon from Northeastern Thailand and Laos. Australian J. Crop Sci. 6(4):717-723.

Rahman MM, Rasaul MG, Hossain MA, Iftekharuddaula KM, Hasegawa H (2012). Molecular Characterization and Genetic Diversity Analysis of Rice (Oryza sativa L.) Using SSR Markers. J. Crop Improv. 26(2):244-257.

Rohlf FJ (2000). NTSYS-pc: Numerical taxonomy and multivariate analysis system. Version 2.1. Exeter Publications, New York, USA.

Rohlf FJ (1993).Numerical taxonomy and multivarieties analysis system NTSys-PC version 1.80 Exeter software, New York.

Sajib AM, Hossain MM, Mosnaz ATMJ, Hossain H, Islam MM, Md. Shamsher Ali MS, Prodhan SH (2012). SSR marker-based molecular characterization and genetic diversity analysis of aromatic landreces of rice (Oryza sativa L.). J. BioSci. Biotech. 1(2):107-116.

Siva R, Kumar K, Rajasekaran C (2013). Genetic diversity study of important Indian rice genotypes using biochemical and molecular markers. Afr. J. Biotechnol. 12(10):1004-1009.

Williams K, Kubelik A, Livak K, Rafalski J, Tingey V (1990). DNA polymorphisms amplified by arbitrary primers are useful as genetic markers. Nucleic Acid Res. 18:6531-6535. 